\title{
Correlation of FNAC and histopathology in diagnosis of salivary gland lesions
}

\author{
Koirala $\mathrm{S}^{1}$, Sayami G' ${ }^{2}$, Pant $\mathrm{AD}^{2}$ \\ ${ }^{1}$ Depatment of Pathology, Nepal Medical College, Kathmandu, Nepal. \\ ${ }^{2}$ Department of Pathology, Tribhuvan University Teaching Hospital, Kathmandu, Nepal.
}

\section{Keywords:}

Salivary gland;

FNAC;

Sensitivity;

Specificity;

Accuracy

\begin{abstract}
Background: Value of fine needle aspiration cytology in preoperative diagnosis of salivary gland lumps has been established in various studies. This study aims to calculate sensitivity, specificity accuracy of FNAC, correlate FNAC findings with histopathology and find out reasons for common diagnostic pitfalls in FNAC.
\end{abstract}

Materials and methods: This study was performed in 67 patients that presented with salivary gland lumps at Department of pathology, Tribhuvan University Teaching Hospital, Institute of medicine, Kathmandu, Nepal from January 2009 to June 2010. FNAC was performed and was correlated with histopathological diagnosis to judge the sensitivity, specificity and accuracy of FNAC.

Results: Out of 36 cases there was cyto-histological correlation in 28 cases. Pleomorphic adenoma was the most frequent lesion in this study. Parotid gland was the most common site affected by salivary gland lesions. The sensitivity, specificity and accuracy for non-neoplastic lesions was $100 \%, 89.28 \%, 91.67 \%$, for benign neoplasms was $100 \%, 86.95 \%, 91.67 \%$ and for malignant neoplasms was $57.14 \%, 100 \%$, $83.33 \%$ respectively.

Conclusion: FNAC is a useful tool in preoperative diagnosis of salivary gland lesions and can be crucial for the management of the patient. Aspiration and reporting of salivary gland lesions demands a competent pathologist who considers all the possible diagnostic pitfalls in mind.

\section{INTRODUCTION}

Approximately $3 \%$ of all head and neck neoplasms are salivary gland tumors. ${ }^{1}$ Clinical examination and imaging without FNAC are not able to distinguish benign from malignant lesions. ${ }^{2}$ The main role of FNAC is to distinguish

\section{Correspondence:}

Dr. Sudhamshu Koirala, MD

Department of Pathology

Nepal Medical College Kathmandu, Nepal benign lesions from malignant neoplasms. Different articles conclude that FNAC is a simple and rapid technique for which expensive instruments are not needed. ${ }^{3}$ FNAC, as a preoperative tool however has its own limitations. The small size of needle contrasts with great variety of salivary gland lesions so the sampled area may not be representative of pathology. ${ }^{4}$ Majority of cells in salivary gland lesions arise from the same cell lines i.e. (epithelial 
and myoepithelial) and often undergo metaplastic changes (squamous, oncocytic, mucinous, sebaceous and chondroid metaplasia) which causes diagnostic problems in FNAC. ${ }^{5}$ The rationale for this study was to identify the diagnostic reliability of FNAC in diagnosing benign and malignant lesions of salivary gland that present during the study period and analyze the reasons for diagnostic pit falls in cases that have cytohistological disagreement.

\section{MATERIALS AND METHODS}

This was a cross-sectional, comparative study done in Department of pathology, Tribhuvan University Teaching Hospital Institute of medicine, Kathmandu, Nepal for duration of 18 months from January 2009 to June 2010. During the study period 67 cases of FNAC of salivary gland lesions were performed out of which in 36 cases cytohistopathological correlation were possible. Air dried FNAC specimens were Giemsa stained and wet smears were stained by Papanicolau method. Histopathological specimen slides were stained using Hematoxylin and Eosin. The slides were examined and diagnosis was made and cytohistopathological correlation was made. FNAC diagnoses were divided into non-neoplastic lesions, benign neoplasms and malignant lesions. Available data were analyzed using SPSS 13.

\section{RESULTS}

Age range varied from 9-85 years.33 (49.2\%) patients were male and 34 were female $(51.8 \%)$. There was no sex predilection for any type of lesion. Non-neoplastic and benign lesions were more prevalent in the age group of 2130 years (fig. 1). Parotid gland was the most common site involved $(\mathrm{N}=33 ; 49.2 \%)$ followed by submandibular gland $(\mathrm{N}=27 ; 45 \%)$. There were seven cases of minor salivary



Figure 1: Age distribution of salivary gland lesions gland lesions $(\mathrm{N}=7 ; 17.9 \%)$. Nonneoplastic lesion comprises 35 cases $(52.2 \%)$ whereas benign and malignant neoplasm constituted $20(29.8 \%)$ and $12(17.9 \%)$ respectively.

Chronic sialadenitis, pleomorphic adeoma, mucoepidermoidcarcinoma was the most common nonneoplastic lesion, benign neoplasm and malignant neoplasm diagnosed in FNAC, respectively. Two cases of minor salivary gland lesions were malignant (28.57\%). Various lesions of salivary glands and cytohistological correlation is shown in table 1 . Out of 36 cases 28 cases had same cytohistological diagnosis $(77.7 \%)$ whereas 8 cases $(22.3)$ had cytohistological disagreement $(22.3 \%)$.

Diagnostic reliability was judged based on sensitivity, specificity and accuracy. Sensitivity in various type of lesion ranged from $57 \%-100 \%$. Specificity in various types of lesion ranged from 86-100\% and accuracy ranged from $83-92 \%$. (Table 2)

\section{DISCUSSION}

Classifying the salivary gland lesions into non-neoplastic, benign and malignant neoplasm may guide the clinician to make correct therapeutic decisions as to which patient requires further investigation, medical treatment or excision. ${ }^{6}$ During the study period 67 patients underwent fine needle aspiration of salivary gland lesions, 36 of these patients underwent surgery and subsequent histopathological examination. The age range in this study varied from 9-85 years. Non-neoplastic lesions and benign neoplasm were common before the age of $50(66.67 \%)$ in comparison to malignant lesion which were more common after the age of $50(58.3 \%)$. In a study in Brazil, authors found malignant tumors peaked in seventh decade; benign tumors peaked in the fourth decade. ${ }^{7}$ A noteworthy case is of acinic cell carcinoma in a 10 year old. According to section on acinic cell carcinoma in WHO publication on head and neck tumors, four percent of the patients with acinic cell carcinoma are under 20 years old. $32(47.76 \%)$ patients were male and 37 patients were female $(52.24 \%)$. There was no clear cut sex predilection for either benign or malignant lesions.Salivary gland lesions in general are however more common in females. ${ }^{2}$ Chronic sialadenitis, pleomorphic adenoma and mucoepidermoid carcinoma were The most common non neoplastic, benign neoplasm and malignant neoplasm respectively. An article on pleomorphic adenoma states that pleomorphic adenoma is the most common salivary gland tumor and comprises about $79 \%$ of the major and $72 \%$ of minor salivary gland tumors. ${ }^{8}$ Klijanienko $\mathrm{J}$ et al in his study found mucoepidermoid carcinoma is one of the most common malignant tumors of salivary glands. ${ }^{9}$ Eight of 36 cases had cyto-histological disagreement. Cystic presentation of lesions was common reason for pitfall. A right parotid lump cystic in consistency was diagnosed as retention cyst due to presence of fluid and 
Table 1: FNAC and Histopathology correlation of salivary gland lesions

\begin{tabular}{|c|c|c|c|c|c|c|c|c|c|c|c|}
\hline \multirow{2}{*}{$\begin{array}{c}\text { FNAC } \\
\text { DIAGNOSIS }\end{array}$} & \multirow{2}{*}{$\begin{array}{l}\text { No. of } \\
\text { Cases }\end{array}$} & \multicolumn{10}{|c|}{ HISTOPATHOLOGICAL DIAGNOSIS } \\
\hline & & $\mathrm{MC}$ & MYC & ACC & EMC & PLGC & $\mathrm{PA}$ & $\mathrm{SC}$ & $\mathrm{BCL}$ & $\mathrm{CS}$ & $\mathrm{CD}$ \\
\hline $\mathrm{CS}$ & 6 & 1 & & & & & & & & 5 & \\
\hline $\mathrm{BCL}$ & 4 & 1 & & & & & & & 3 & & \\
\hline $\mathrm{AB}$ & 1 & & & & 1 & & & & & & \\
\hline RL & 1 & & & & & & & & & & 1 \\
\hline PA & 15 & 1 & 1 & & & & 12 & 1 & & & \\
\hline WT & 1 & 1 & & & & & & & & & \\
\hline $\mathrm{MC}$ & 5 & 5 & & & & & & & & & \\
\hline PLGC & 1 & & & & & 1 & & & & & \\
\hline ACC & 2 & & & 2 & & & & & & & \\
\hline TOTAL & 36 & 9 & 1 & 2 & 1 & 1 & 12 & 1 & 3 & 5 & 1 \\
\hline
\end{tabular}

AB : Abscess, ACC: Acinic cellcarcinoma, BCL : Benign cystic lesion, CD : Castleman's disease, CS : Castleman's disease, EMC : Epithelial Myoepithelial Carcinoma, MC : Mucoepidermoid carcinoma, MYC : Myoepithelial carcinoma, PA: Pleomorphic adenoma, PLGC: Polymorphous Low Grade Carcinoma, RL: Reactive lymphadenitis, SC: Schwannoma, WT: Warthin,s tumor

\begin{tabular}{|c|c|c|c|}
\hline & SENSITIVITY & SPECIFICITY & ACCURACY \\
\hline $\begin{array}{l}\text { Non-neoplastic } \\
\text { lesions }\end{array}$ & 100 & 89.28 & 91.67 \\
\hline Benign neoplasm & 100 & 86.95 & \\
\hline Malignant neoplasm & 100 & 86.95 & \\
\hline
\end{tabular}

histiocytes in aspiration smear. Histopathological diagnosis was acinic cell carcinoma, microcystic variant. Ali ZS et al studied FNAC smears of seven cases acinic cell carcinomas diagnosed on histopathology. Two of the seven cases in his study showed cystic material and histiocytes only. ${ }^{10}$ Another case of tender cystic right parotid lump diagnosed as abscess in FNAC was proven to be epithelial and myoepithelial carcinoma that had gone cystic degeneration with subsequent infection. Tongeren JV et al, reported a case of bilateral synchronous epithelial-myoepihelial carcinoma which had cystic presentation..$^{10}$ Pleomorphic adenoma usually show good cyto-histo correlation. However when the FNAC smears from pleomorphic adenoma predominately show spindle cells in a myxoid background rarer lesions like myoepithelial neoplasm and schwannoma should come into differential diagnosis as happened with two of the cases.

Similar erroneous diagnosis pleomorphic adenoma in cases of myoepithelial carcinoma and schwannoma have been described been described. ${ }^{8,11,12}$

Presence of mucin in aspirate that otherwise appeared typical of pleomorphic adenoma turned out to be case of mucoepidermoid carcinoma. An article by Handa $U$ et al states that cystic degeneration and mucin production are common in pleomorphic adenoma. ${ }^{8}$ A case of myoepithelial carcinoma was missed due to presence of spindle cells that a were thought to be fibroblasts in background of chronic inflammatory cells in FNAC. FNAC diagnosis was chronic sialadenitis. Intermediate cells of mucoepidermoid carcinoma were reported as oncocytic in FNA smears thus resulting in false diagnosis of Warthin's tumor and a case diagnosed as reactive lymphadenitis of intraparotid lymph node turned out to be Castleman's disease in biopsy. Warthin's tumor is a common false negative diagnosis in cases of mucoepidermoid carcinoma. ${ }^{13}$

In a case similar to ours FNAC smears of that reported case were suggestive of reactive lymphadenitis of the intraparotid lymph node and the diagnosis of Castleman's disease was only possible on biopsy. ${ }^{14}$

The sensitivity, specificity and accuracy for non-neoplastic lesions were $100 \%, 89.28 \%, 91.67 \%$, for benign neoplasms were $100 \%, 86.95 \%, 91.67 \%$ and for malignant neoplasms were $57.14 \%, 100 \%, 83.33 \%$ respectively. According to the various authors, the accuracy of needle aspiration in malignant tumors range from $80.4 \%$ to $97 \%$, sensitivity from $54 \%$ to $97.6 \%$ and specificity from $86 \%$ to $100 \%$ respectively. ${ }^{15-17}$

\section{CONCLUSION}

FNAC can be used as preoperative investigations of salivary gland lesions. It can be used to differentiate benign from malignant lesions preoperatively. Type specific diagnosis are more difficult in malignant cases, however as seen from this study absence of malignancy can be correctly identified in fine needle aspirations.

\section{REFERENCES}

1. Leegaard T, Lindean H. Salivary gland tumors: clinical picture and treatment. Acta Otolaryngol 1970; 263:155-9. Crossref 
2. Odile D, Saad B, Matthew H. Parotid Gland Fine-Needle Aspiration Cytology: an approach to differential diagnosis. Diagn Cytopathol 2006;35:47-56.

3. Mavec P, Eneroth C-M, Franzen S, Moberger G, Zajicek J. Aspiration biopsy of salivary gland tumors I: correlation of cytologic reports from 652 aspiration biopsies with clinical and histological findings. Acta Otolaryngol Stokh 1964;58:472-84.

4. Zurrida S, Alasio L, Tradafi N, Bartoli C, Chies F, Pilotti S. Fineneedle aspiration of parotid masses. Cancer 1993;72:2306-11. Crossref

5. Theodore RM. FNA of Salivary Gland: problems and pitfalls. Crossref

6. Mavec P, Eneroth C-M, Franzen S, Moberger G, Zajicek J. Aspiration biopsy of salivary gland tumors I : correlation of cytologic reports from 652 aspiration biopsies with clinical and histologic findings. Acta Otolaryngol Stockh 1964;58:471-84. Crossref

7. De Oliveir FA, Duarte ECA, Taveira CT et al. Salivary gland tumor: a review of 599 cases in a Brazilian population. Head and Neck Pathol 2009; 3:271-5. Crossref

8. Handa U, Dhingra N, Chopra R, Mohan H. Pleomorphic Adenoma: cytologic variations and potential diagnostic pitfalls. Diagn Cytopathol 2008;37:11-5. Crossref

9. Klijanienko J, Vielh P. Fine-Needle sampling of salivary gland lesions IV: review of 50 cases of Mucoepidermoid carcinoma with histologic correlation. Diagn Cytopathol1997;17:92-8. Crossref

10. Tongeren Jv, Creytens DHKV, Meulemans EV, de bondt RBJ, deJong J, Manni JJ. Synchronous bilateral epithelial-myoepithelial carcinoma of the parotid gland: case report and review of the literature. European archives of Otorhinolaryngol 2009;226:1495500 .

11. Di palma S, Alasio 1, Pilotti S. Fine needle aspiration (FNA) appearances of malignant myoepithelioma of the parotid gland. Cytopathol 1996;7:357-65. Crossref
12. Chhieng DC, Paulino AF. Cytology of myoepithelial carcinoma of the salivary gland: a study of four cases. Cancer Cytopathol 2002;96:32-6. Crossref

13. Ballo MS, Shin JHC, Sneige N. Sources of diagnostic error in the Fine-Needle aspiration diagnosis of Warthin's Tumor and clues to a correct diagnosis. Diagn Cytopathol1997;17:230-4. Crossref

14. Chan MKM, Lloyd JM. Cytodiagnosis of lesions presenting as salivary gland swellings: a report of seven cases. Diagn cytopathol 1991;8:439-43. Crossref

15. Filipoulos E, Angeli S, Daskalopulon D, Kelessis N, Vassilopoulos P. Preoperative evaluation of parotid tumors by fine-needle biopsy. Eur J SurgOncol 1998;24:180-3. Crossref

16. Pitts DB, Hilsinger RL, Karandy E, Ross JL, Caro JE. Fine needle aspiration in the diagnosis of salivary gland disorders in the community hospital setting. Arch Otolaryngol HeadNeck Surg 1992;118:479-82. Crossref

17. Atula T, Grenman R, Laippala P, Klemi PJ. Fine needle aspiration biopsy in the diagnosis of parotid gland lesions. Diagn Cytopathol 1991;15:185-90. Crossref 